\title{
EVALUATION OF THE CLINICAL EFFICACY OF COLLAGEN MEMBRANE IN COMBINATION WITH BONE GRAFTS IN THE TREATMENT OF MILLER'S CLASS I /II MARGINAL TISSUE RECESSION: A CASE REPORT
}

Yash Paul Dev ${ }^{1}$, Nitin Khuller ${ }^{2}$, Preetinder Singh ${ }^{3}$, Prabhjot Kaur ${ }^{4}$, Yashbir Singh Raghav ${ }^{5}$, Anahita Singh

${ }^{1}$ Principal \& Head, Department of Periodontology, Swami Devi Dyal Hospital \& Dental College, Haryana, India

${ }^{2,3}$ Reader, Department of Periodontology, Swami Devi Dyal Hospital \& Dental College, Haryana, India

${ }^{4,5,6}$ Post Graduate Student, Department of Periodontology, Swami Devi Dyal Hospital \& Dental College, Haryana, India

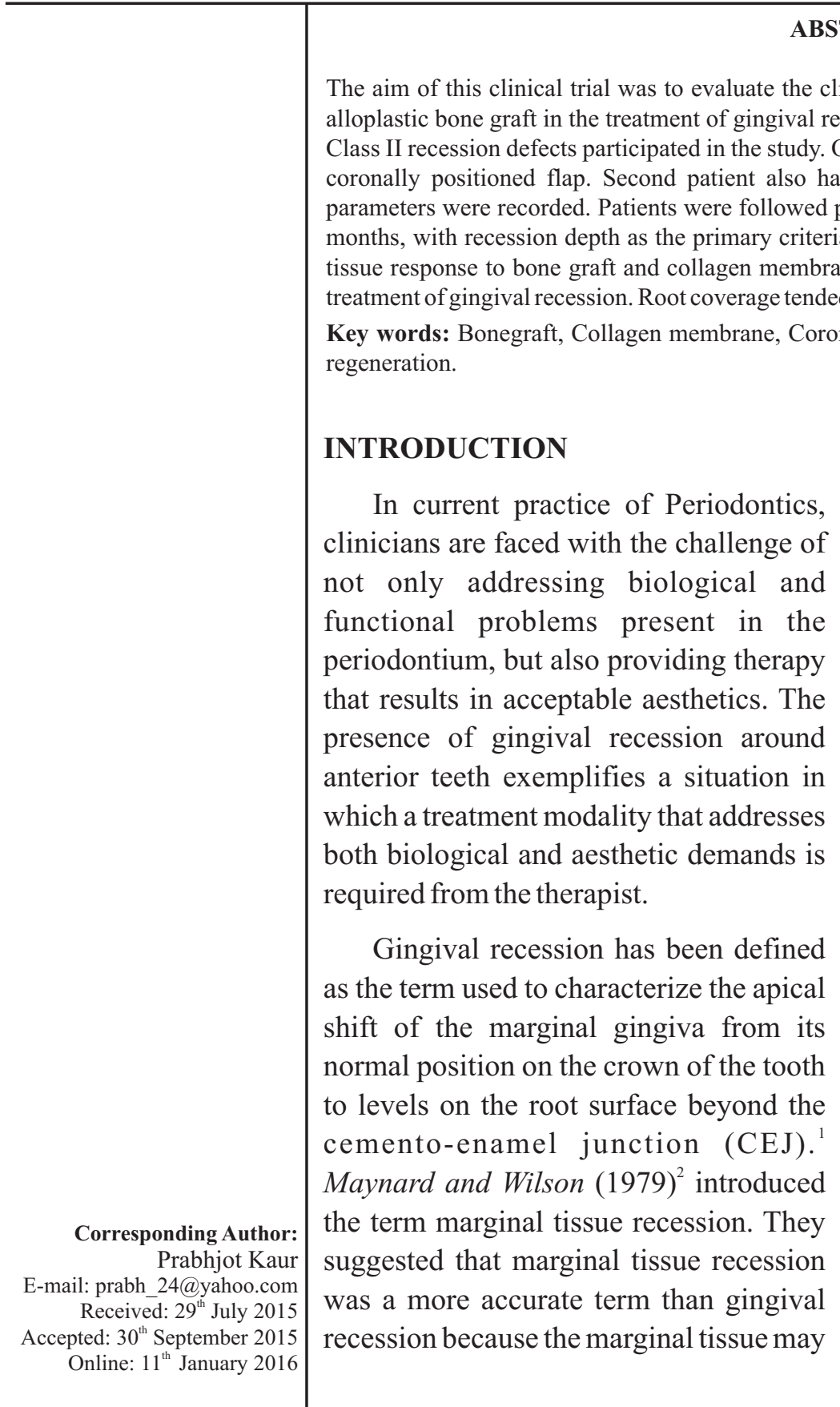

ABSTRACT

The aim of this clinical trial was to evaluate the clinical effectiveness of a collagen barrier along with an alloplastic bone graft in the treatment of gingival recession defects. Two patients having Miller's Class I or

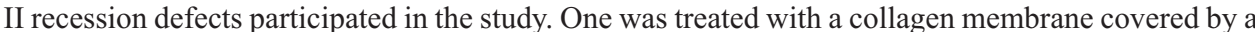
treatment of gingival recession. Root coverage tended to be better with the addition of bone graft.

Key words: Bonegraft, Collagen membrane, Coronally advanced flap, Gingival recession, Guided tissue egeneration.

\section{INTRODUCTION}

In current practice of Periodontics, clinicians are faced with the challenge of nt only addressing biological and periodontium, but also providing therapy periodontium, but also providing therapy that results in acceptable aesthetics. The presence of gingival recession around situation in atdresses both biological and aesthetic demands is

Gingival recession has been defined s the term used to characterize the apical shift of the marginal gingiva from its normal position on the crown of the tooth to levels on the root surface beyond the cemento-enamel junction (CEJ). Maynard and Wilson (1979) $)^{2}$ introduced the term marginal tissue recession. They epted: 30 September 2015 Online: 11 January 2016 originally have been alveolar mucosa rather than gingiva. ${ }^{2}$ The ultimate goal of periodontal therapy includes not only the arrest of progressive periodontal disease but also the restitution of those parts of the supporting apparatus which have been destroyed by the disease. ${ }^{3}$

Gingival recession defects may be treated by a number of procedures including rotational and advanced gingival flaps, free gingival or connective tissue grafts, and by applying principles of guided tissue regeneration (GTR). ${ }^{4}$ The coronally advanced flap is the surgical technique of first choice when there is adequate keratinized tissue apical to the recession defect. ${ }^{5}$ Optimum root coverage results, good colour blending of the treated area with respect to adjacent soft tissues and complete recovery of the original (pre-surgical) soft tissue marginal morphology can be predictably accomplished by means of this surgical approach. 
Recently, attempts have been made to achieve root coverage using surgical techniques based on the principles of guided tissue regeneration (GTR). ${ }^{6}$ The theoretical principles basic to GTR were first described in 1976 by Melcher who outlined the necessity of excluding the unwanted cell lines from healing sites to allow the growth of desired tissues.

Collagen membranes have been successfully used for GTR based root coverage. Complete root coverage is considered the true goal of treatment because only complete coverage assures recovery from the hypersensitivity and aesthetic defects associated with recession areas.

Kimble $\mathrm{KM}$ et $\mathrm{al}^{7}$ achieved $73 \%$ root coverage using collagen membranes with coronally advanced flaps. Studies have tried to improve the percentages of complete coverage with root surface bio-modification. Various agents that have been used are: citric acid, tetracyclines and ethylene-di-amine-tetra-acetic acid (EDTA). EDTA is a chelating agent that could enhance the attachment of connective tissue to the root surface by exposing collagen and, as a consequence, enhance root coverage. ${ }^{8}$

Creation and maintenance of space between the root surface and the overlying GTR barriers are considered critical to the success of all GTR procedures, including those aimed at achieving root coverage. It is believed that this space is necessary to provide a channel for the migration of progenitor cells towards and onto the detoxified root surface, where they can differentiate into cementum and periodontal ligament forming cells. Unfortunately, it is difficult to achieve space maintenance when treating recession defects because the membrane tends to collapse against the root surface. Several techniques have been used to provide space for regenerating tissue: root modification, tenting sutures, fibrin-fibronectin glue, titanium- reinforced membranes, and bone grafts. The rationale for using bone graft beneath a membrane is that it can prevent collapse of the membrane into the defect, reduce the volume to be filled by regenerating cells, enhance clot stability, and stimulate and facilitate the proliferation of osteogenic progenitor cells.
Since there is limited literature on the use of type I collagen membranes combined with bone grafts for the treatment of gingival recession, a study was conducted to determine whether the addition of bone graft (i.e. Sybograf Plus) significantly influences the clinical outcome of GTR- based root coverage procedures using collagen membranes (i.e. Healiguide ${ }^{\mathrm{TM}}$ ) $^{* *}$ or not.

\section{Case report}

Two patients, a 25-years-old systemically healthy male and a 32 years old male, with Miller's Class II gingival recession of $3 \mathrm{~mm}$ depth in upper left canines were selected from patients seeking treatment for root coverage from Out Patient Department (OPD) of Periodontology and Oral Implantology, Swami Devi Dyal Hospital and Dental College, Barwala, Panchkula.

The subjects were clearly explained regarding the study protocol and procedure in detail and a duly signed written consent was taken from them. Following screening examination, the subjects were given proper oral hygiene instructions.

The materials used in the study consisted of: collagen membrane (Healiguide ${ }^{\mathrm{TM}}$ ), bone graft containing nanocrystalline hydroxyapatite and $\beta$ tricalcium phosphate (Sybograf Plus), 24\% EDTA as root biomodifier and 4-0 vicryl suture.

Custom made acrylic stents were fabricated on plaster/ stone casts to ensure reproducibility of parameters recorded at subsequent visits.

The following clinical parameters were recorded for each site at baseline, $1^{\text {st }}$ month, 3 rd month and $6^{\text {th }}$ month post-operative:

a) Plaque Index (PI) (Silness P, Loe H 1964) at baseline, $1^{\text {st }}, 3^{\text {rd }}$ and $6^{\text {th }}$ month.

b) Modified Gingival Index (mGI) (Lobene RR et al 1986) at baseline, $1^{\text {st }}, 3^{\text {rd }}$ and $6^{\text {th }}$ month.

c) Modified Sulcular Bleeding Index (mSBI) (Mombelli et al 1987) at baseline, $1^{\text {st }}, 3^{\text {rd }}$ and $6^{\text {th }}$ month.

d) Probing Depth (PD) at baseline, $3^{\text {rd }}$ and $6^{\text {th }}$ month.

e) Recession Depth (RD) at baseline, $3^{\text {rd }}$ and $6^{\text {th }}$ month. 
f) Recession Width at the widest point (RW) at baseline, $3^{\text {rd }}$ and $6^{\text {th }}$ month.

g) Width of Keratinised Tissue (WKT) at baseline, $3^{\text {rd }}$ and $6^{\text {th }}$ month.

h) Clinical Attachment Level (CAL) at baseline, $3^{\text {rd }}$ and $6^{\text {th }}$ month.

\section{Surgical Procedure}

The two patients were randomly allotted numbers as patient 1 and patient 2. Patient 1 was treated with GTR only and patient 2 was treated with GTR and bone graft both.

Patient 1: After evaluation of pre-clinical records and obtaining adequate local anaesthesia, a trapezoidalshaped flap was elevated with a split-full-split approach from the coronal to apical direction. The probable sulcular area apical to the root exposure was elevated by split thickness flap keeping the blade almost parallel to the root. The soft tissue apical to the root exposure was elevated by full thickness flap. For this, a small periosteal elevator was inserted into the probable sulcus, proceeding in the apical direction to expose 3-4 $\mathrm{mm}$ of bone apical to the bone dehiscence. In order to permit the coronal advancement of the flap, all muscle insertions present in the thickness of the flap were dissected. Coronal mobilization of the flap was considered "adequate" when the marginal portion of the flap passively reached a level coronal to the CEJ of the tooth with the recession defect. ${ }^{9}$ The exposed root surface, after thorough root planing, was conditioned with ethylene-di-amine-tetra-acetic acid (EDTA-24\%) for 2 minutes to remove the smear layer and then thoroughly rinsed with sterile saline. Any remaining periodontal tissue coronal to the alveolar bone was preserved. The collagen membrane was then placed according to standard GTR surgical protocol and sutured bilaterally to the de-epithelialized papilla region with 4-0 vicryl suture. Subsequently, the membrane was covered with the coronally advanced flap. The tissue flap was then secured at the level of the CEJ by suturing the flap to the de-epithelialized papilla regions with 4-0 vicryl sutures. The vertical incisions were also closed with 4-0 vicryl sutures. The surgical site was then covered with a periodontal dressing.
Patients were given post-operative instructions and medicines were prescribed (ibuprofen s.o.s) and mouthwash was also prescribed (chlorhexidine twice daily) ${ }^{9}$ (Figure 1).

Patient 2: similar procedure was performed in patient 2. The difference lied only in the placement of bone graft i.e. before placing the membrane; the bone graft was placed over the exposed root surface and to the coronal ligament fibres. Rest of the whole procedure was same (Figure 2).

\section{Post-Surgical Follow up:}

Patients were called after 24 hours for check up to evaluate any discomfort, swelling, pain, bleeding or displacement of periodontal pack. One week following surgery, periodontal pack was removed and area was irrigated with saline. Patients were recalled every 2 weeks following surgery for 1 month and subsequently every month for the next 6 months for examination of the treated surgical site. Clinical parameters recorded at baseline were recorded again at intervals of 1 month, 3 month and 6 months post-surgery.

RESULTS (Figure 3 and 4)

Various parameters recorded at baseline and different time intervals are shown in the table 1 . The results indicated that for patient 2 (GTR and bone graft), there was $90 \%$ reduction in gingival recession depth and appreciable reduction was also seen for values of CAL, PD and WKT when compared from baseline to 6 months. On the other hand, only $70 \%$ reduction in recession depth was observed for patient 1 (GTR only). The tissues at surgical sites of both the patients appeared healthy, with no visible signs of inflammation.

\section{DISCUSSION}

Clinical parameters (i.e. PI, $\mathrm{mGI}$ and $\mathrm{mSBI}$ ) remained relatively constant at all the time intervals during the study period, suggesting that surgically positioned collagen membrane was well- tolerated by the host tissues. These findings are in agreement with Blumenthal (1993) ${ }^{10}$, Sheih AT et al (1997) ${ }^{6}$, Kimble K et al (2004) ${ }^{7}$ and Nandita $\mathrm{S}$ et al (2011) ${ }^{11}$ who reported that the placement of collagen membranes doesn't 


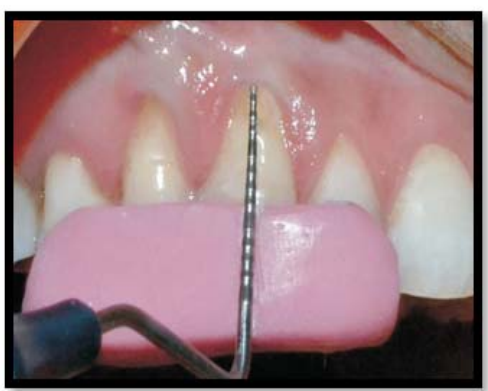

Figure 1(a): Recession Depth at baseline

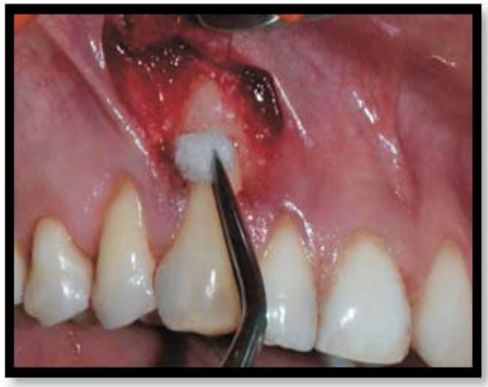

Figure 1(d): Application of 24\% EDTA

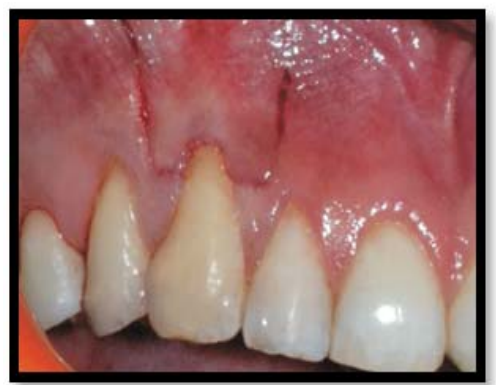

Figure 1(b): Incisions given

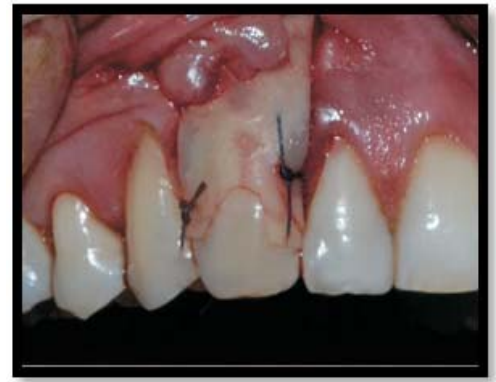

Figure 1(e): Collagen membrane secured with sutures

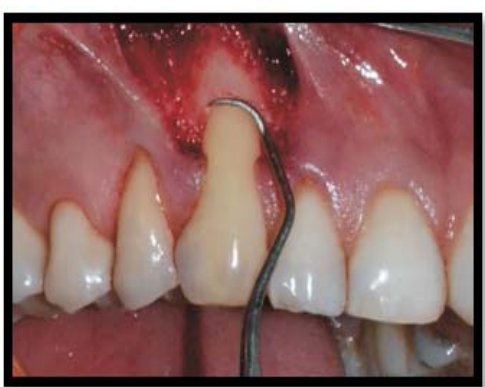

Figure 1(c): Root planning done

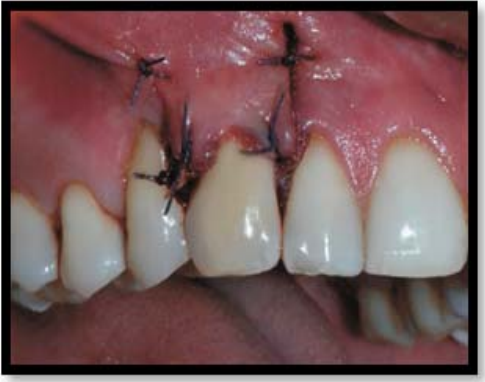

Figure 1(f): Coronal advancement of the flap and secured with sutures.

Figure 1: Surgical Procedure for Patient 1 (GTR Only)

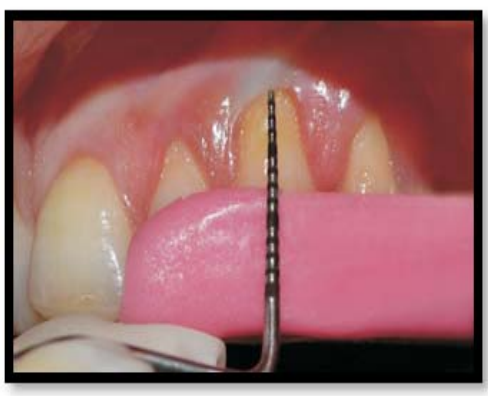

Figure 2(a): Recession Depth at baseline

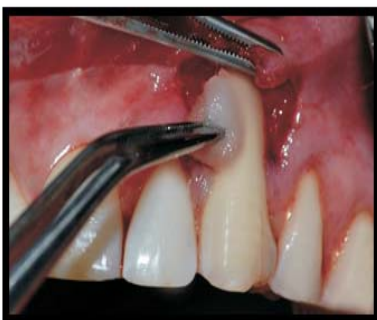

Figure 2(d): Application of $24 \%$ EDTA

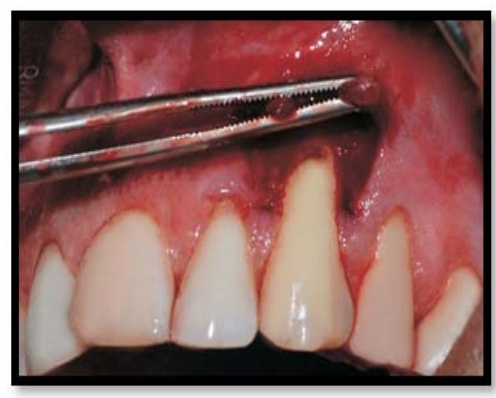

Figure 2(b): Flap reflected

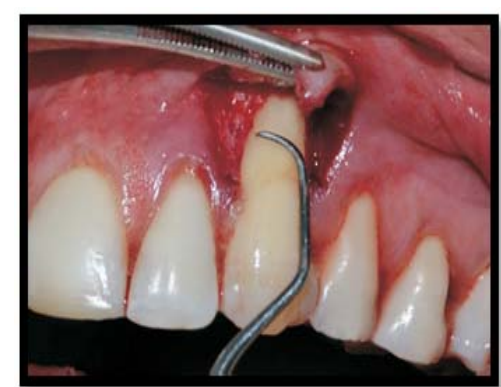

Figure 2(c): Root planing done

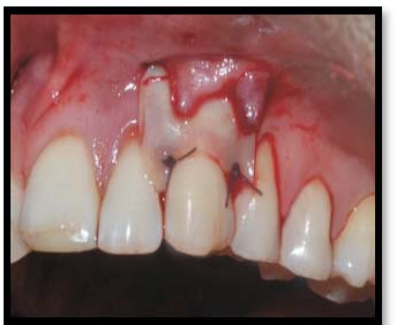

Figure 2(e): Collagen membrane secured with sutures

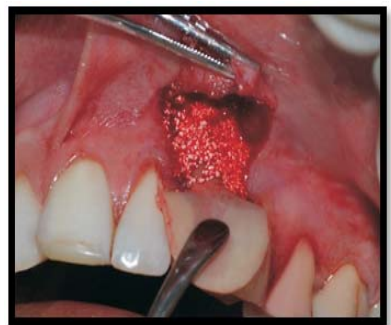

Figure 2(f): Bone graft (Sybograf Plus) placed underneath membrane

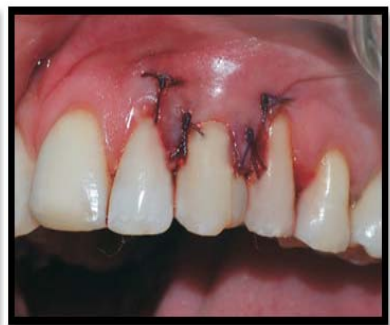

Figure 2(g): Coronal advancement of the flap and secured with sutures.

Figure 2: Surgical Procedure for Patient 2 (GTR and Bone Graft) 


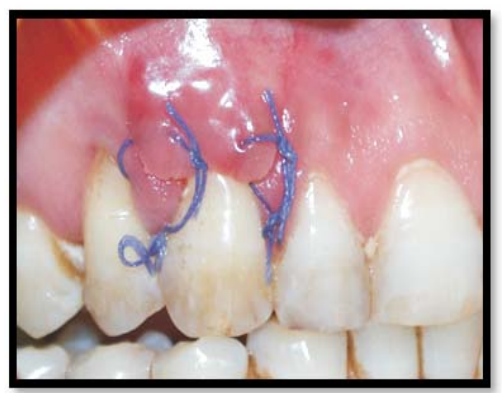

Figure 3(a): 1st month follow up

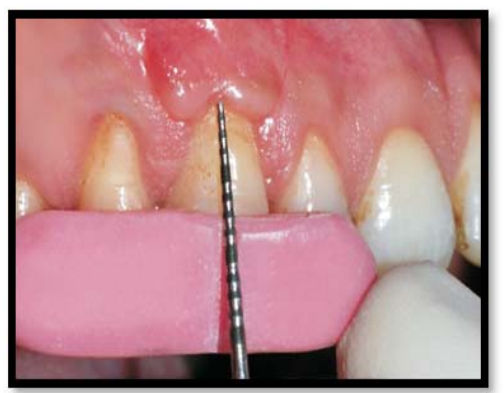

Figure 3(b): Recession Depth at 3 months

Figure 3: Follow Up of Patient 1

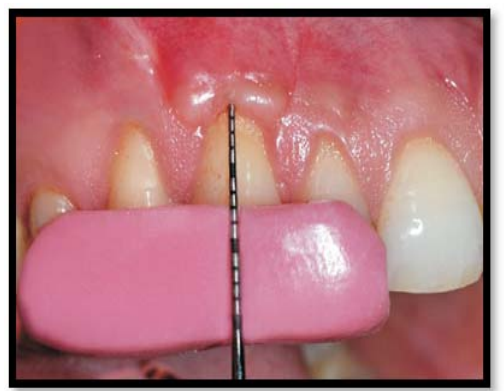

Figure 3(c): Recession Depth at 6 months

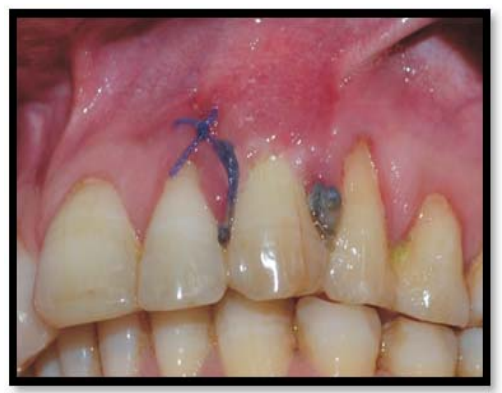

Figure 4(a): 1st month follow up

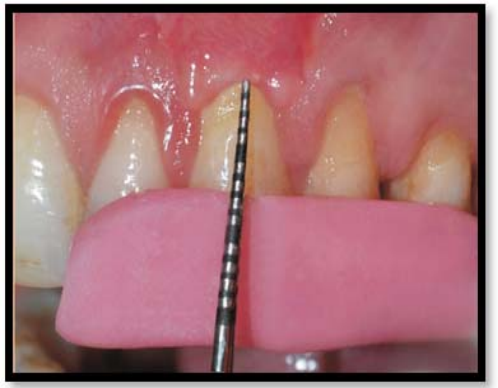

Figure 4(b): Recession Depth at 3

Figure 4(b): Recession
months

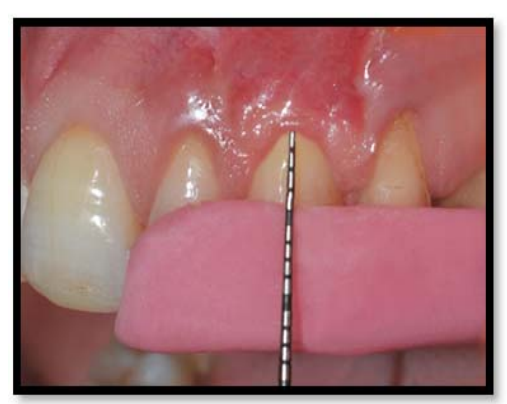

Figure 4(c): Recession Depth at 6 months

Figure 4: Follow Up of Patient 2

Table 1: Showing periodontal parameters at different time intervals.

\begin{tabular}{|l|c|c|c|c|c|c|c|c|}
\hline & PI & GI & mSBI & PD & RD & RW & WKT & CAL \\
\hline \multicolumn{8}{|c|}{ PATIENT 1 (GTR only) } & \multicolumn{2}{c|}{} \\
\hline BASELINE & 1.1 & 0.8 & 1.2 & 3 & 2 & 3 & 3 & 5 \\
\hline $1^{\text {st }}$ month & 1.9 & 1.8 & 1.5 & & & & & \\
\hline $3^{\text {rd }}$ month & 1.4 & 1.5 & 1.5 & 1 & 2 & 3 & 5 & 3 \\
\hline $6^{\text {th }}$ month & 1 & 1.1 & 0.4 & 1 & 1 & 3 & 5 & 2 \\
\hline \multicolumn{8}{|c|}{ PATIENT 2 (GTR and bone graft) } \\
\hline BASELINE & 0.9 & 0.8 & 1 & 4 & 4 & 4 & 2 & 4 \\
\hline $1^{\text {st }}$ month & 1.3 & 1.7 & 1.3 & & & & & 5 \\
\hline $3^{\text {rd }}$ month & 1.1 & 0.9 & 1.2 & 2 & 2 & 3 & 5 & 4 \\
\hline $6^{\text {th }}$ month & 0.7 & 1.1 & 0.4 & 1 & 0 & 1 & 7 & 0 \\
\hline
\end{tabular}

cementum formation, and new coronal bone growth. Numerous studies support the concept that to obtain periodontal regeneration, adequate space needs to be maintained underneath the membrane. ${ }^{6}$ The creation and maintenance of a space between the root surface and the overlying GTR barrier is considered essential to the success of guided tissue regeneration therapy. This space is believed to be necessary to provide a channel for the migration of progenitor cells toward and onto the detoxified root surface where differentiation of cementoblasts and formation of new cementum/ periodontal ligament is desired. Unfortunately, space preservation in recession defects is often difficult to achieve because the morphology of the dehiscence tends to allow collapse of the membrane against the root surface. The use of a biocompatible graft material may increase this space and favor new bone formation. Also, alloplast has been shown to have osteoconductive 
potential. The combination of a membrane and alloplastic bone graft for the treatment of periodontal defects has been shown in some studies to result in greater bone formation than membrane treatment alone. ${ }^{7,11,13}$ The results of this study seem to support these findings. Even with the small amount of graft material used on the root surface the difference was significant. The concept of space maintenance underneath the membrane may also be the reason that why it resulted in a significant increase in tissue thickness.

\section{CONCLUSION}

Overall, this study suggests that the treatment of human gingival recession using a bio-absorbable membrane with or without the use of bone graft results in significant root coverage. Addition of bone graft as space maintainer proves to be effective in such cases of root coverage. The present study was a short term clinical study with no histological evaluation. Future studies of such nature should be designed with large sample sizes and histological evaluation to further compare the predictability of these procedures.

\section{REFERENCES}

1. Loe H, Anerud A, Boysen H. The natural history of periodontal disease in man: Prevalence, severity and extent of gingival recession. J Periodontol 1992; 63: 489-495

2. Miller PD. A Classification of Marginal Tissue Recession. Int J Periodontics Restorative Dent 1985;2:9-13

3. Carvalho MD. Platelet-rich plasma plus bioactive glass in the treatment of intra-bony defects: a study in dogs. J Appl Oral Sci. 2011; 19:82-89

4. Meyer MJ, Wikesjo UME. Gingival recession defects and guided tissue regeneration: a review. J Periodontal Res 2001; $36: 341-354$
5. Zucchelli G, Cesari C, Amore C, Montebugnoli L, Sanctis MD. Laterally Moved, Coronally Advanced Flap: A Modified Surgical Approach for Isolated Recession-Type Defects. J Periodontol 2004; 75:1734-1741

6. Shieh AT, Wang HL, O'Neil R, Glickman GN, MacNeil RL. Development and clinical evaluation of a root coverage procedure using a collagen barrier membrane. J Periodontol 1997; 68: 770-778

7. Kimble KM, Eber RM, Sochren S, Shyr Y, Wang HL. Treatment of gingival recession using collagen membrane with or without the use of Demineralised Freeze- Dried Bone Allograft for space maintenance. J Periodontol 2004; 75:210 218

8. Bittencourt S. Root Surface Biomodification with EDTA for the Treatment of Gingival Recession with a Semilunar Coronally Repositioned Flap. J Periodontol 2007; 78:16951701

9. Gottlow J, Nyman S, Kaning T, Lindhe J. New attachment formation as the result of controlled tissue regeneration. J Clin Periodontol 1984: 11: 494-503

10. Blumenthal NM. A clinical comparison of collagen membranes with e-PTFE membrane in the treatment of human mandibular buccal class II furcation defects. J Periodontol 1993; 64: 925-933

11. Nanditha S, Priya MS, Sabitha S, Arun KV, Avaneendra T. Clinical evaluation of the efficacy of a GTR membrane (Healiguide) and demineralised bone matrix (Osseograft) as a space maintainer in the treatment of Miller's Class I gingival recession. Journal of Indian Society of Peiodontology 2011; $15: 156-160$

12. Lee EJ, Meraw SJ, Giannobile WV, Wang HL. Comparative histologic analysis of coronally advanced flap with and without collagen membrane for root coverage. J Periodontol 2002; 73: 779-788

13. Duval BT, Maynard J, Gunsolley JC, Waldrop TC. Treatment of Human Mucogingival Defects Utilizing a Bioabsorable Membrane With and Without a Demineralized Freeze-Dried Bone Allograft. J Periodontal 2000; 71:1687-1692 